\title{
Estimation of stature from direct length of five digits of hand
}

\author{
Pranab Debbarma ${ }^{1}$, Nirmalya Saha ${ }^{2}$, Ambath D. Momin $^{3}$, \\ Moirangthem Matum Singh. ${ }^{4}$ \\ 1, 2. Assistant Professor, 3. Senior Resident, 4. Professor \\ ${ }^{I}$ Department of Anatomy, Agartala Govt' Medical College \& G. B. P. Hospital, Agartala, Tripura, India; \\ ${ }^{2}$ Department of Anatomy, Tripura Medical College \& Dr. B. R. A. M. Teaching Hospital, Hapania, \\ Tripura, India. \\ ${ }^{3}$ Department of Anatomy North Eastern Indira Gandhi Research Institute of Medical Sciences, Shillong, \\ Meghalaya, India; \\ ${ }^{4}$ Department of Anatomy, Regional Institute of Medical Sciences, Imphal, Manipur, India.
}

\begin{abstract}
Stature, important criteria for establishing identity, can be measured from the direct height of the individual. The study of the five digits of both hands in male and female was carried out among 100 first year medical students (55 males and 45 females) in Regional Institute of Medical Sciences, Imphal to determine the stature. Prior permission from the concerned authority and Institutional Ethics Committee had been taken. The digit length of both hands was measured from proximal crease of digit to the tip using a sliding caliper. The individual height was measured by height measuring scale. The estimated height by multiplying the total digital length with five (05) in both right and left hands were found to be similar with the measured height. Pearson correlation analysis had suggested highly positive statistical significant correlation between estimated height and measured height in all participants, males and females. So, this can be concluded that the equation may be helpful to obtain approximate stature when there is difficulty in obtaining a direct measurement or an amputed hand with intact all digits are available. This can be immensely useful in forensic anthropology and any anthropological research.
\end{abstract}

Keywords: Anthropometer, Caliper, Digit, Frankfurt Plane, Stature.

\section{Introduction}

Prediction and estimation of stature has a significant importance in the field of forensic anthropometry. Establishing the identity of an individual from mutilated, decomposed and amputed body fragments has become an important necessity in recent times due to natural or manmade calamities and medical jurisprudence. ${ }^{1,2,3}$ Stature estimation is easy for a person or a complete dead body but difficult arises with some available parts of the body. Identification occupies relatively a central position in anthropological research. ${ }^{3}$ Many factors like racial, ethnic and nutritional factors play an important role for development and growth of human being affecting the stature in different population. ${ }^{4}$ Length of the fingers in an individual enables to establish stature in mutilated body especially when five digits of hand is intact and most of the other parts are missing and damaged. Estimation of stature from finger and phalangeal length had been reported. ${ }^{4}$ Very few data is available on previous works done for calculation of stature from finger length. Number of multiplication factors and regression equations has been developed to reconstruct structure from long bones throughout the world. So, this study was aimed to establish correlation between total length of five digits of hands and stature with a multiplication factor.

\section{Materials and Methods}

With a formal permission from Institutional Ethics Committee and consent from individual participant with full explanation of the purpose of the study, the study was conducted among first year medical students of 2013-2014 batch in the Department of Anatomy, Regional Institute of Medical Sciences, Imphal, Manipur. A total 100 students (55 males and 45 females) of 18 to 20 year of age had participated. Significant deformities of digits and stature were excluded. Individual height (in $\mathrm{cm}$ ) was measured as vertical distance from the vertex to the heel making the participant stand erect on the plane floor with bare foot with shoulder blocks and buttocks touching the wall, Palms of hand turned inwards and fingers horizontally pointing downward. Anthropometer was placed in straight vertical position in front of the subject with the head oriented in eye-ear-eye plane (Frankfurt Plane). The movable rod of the anthropometer was brought in contact with vertex in the mid sagittal plane. $^{2}$

The length (in $\mathrm{cm}$ ) of the five digits of rights and left hands were measured with the help of sliding caliper. The distance from the proximal flexor crease till the tip of the finger was taken as digital length. The stature was estimated from the five digits length by a hypothesized formula as follows: Estimated Stature (ES) 
$=$ Total length of five digits of right/left hand $\mathrm{x} 5$. All the measured data were entered and statistical analysis done by SPSS version 17.0.
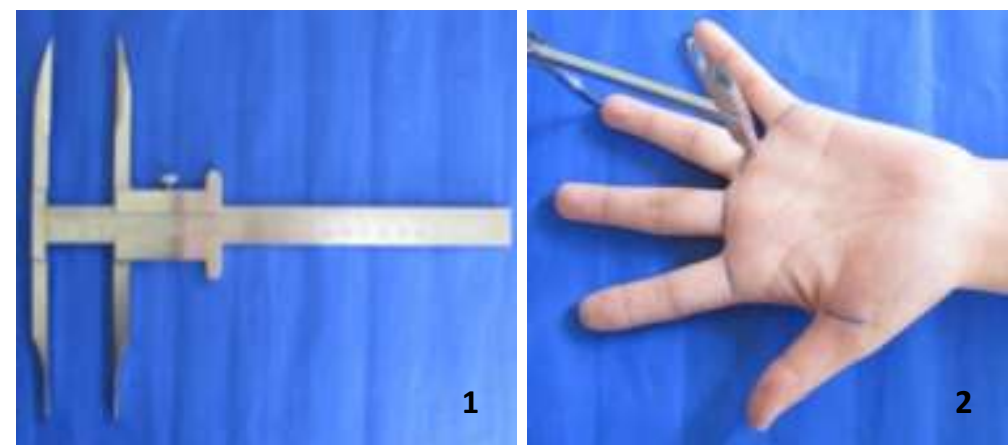

Fig: (1) Sliding calliper, (2) Measurement of digital length from proximal flexor crease of digit to the tip of finger by sliding calliper.

\section{Results and Observations}

The height of the individual was measured. The height was found higher in males $(167.52 \pm 7.81 \mathrm{~cm})$ compared to females (156.46 \pm 5.98$)$. The total digital length also was found more in males than females for both the hands.

Table 1: Showing Mean and Standard Deviation (SD) of the parameters.

\begin{tabular}{|c|l|c|c|c|}
\hline $\begin{array}{c}\text { SI } \\
\text { No }\end{array}$ & \multicolumn{1}{|c|}{ Parameter } & $\begin{array}{c}\text { Total } \\
\text { participants } \\
(\mathbf{n = 1 0 0})\end{array}$ & $\begin{array}{c}\text { Males } \\
(\mathbf{n = 5 5})\end{array}$ & $\begin{array}{c}\text { Females } \\
(\mathbf{n = 4 5})\end{array}$ \\
\hline 1 & Measured Height & $162.67 \pm 9.01$ & $167.52 \pm 7.81$ & $156.46 \pm 5.98$ \\
\hline 2 & Total Length of Digit (Right) & $32.63 \pm 1.85$ & $33.50 \pm 1.59$ & $31.58 \pm 1.59$ \\
\hline 3 & Total Length of Digit (Left) & $32.52 \pm 1.80$ & $33.54 \pm 1.55$ & $31.28 \pm 1.23$ \\
\hline 4 & $\begin{array}{l}\text { Estimated Height By Digits } \\
\text { Right) }\end{array}$ & $162.66 \pm 8.88$ & $167.52 \pm 7.98$ & $156.70 \pm 5.77$ \\
\hline 5 & Estimated Height By Digits (Left) & $162.58 \pm 9.01$ & $167.71 \pm 7.74$ & $156.30 \pm 6.01$ \\
\hline
\end{tabular}

Table 2: Correlation analysis in between measured height and estimated height.

\begin{tabular}{|l|l|l|l|}
\hline Parameters & $\begin{array}{l}\text { Estimated height in } \\
\text { total participants } \\
(\mathbf{n}=\mathbf{1 0 0})\end{array}$ & $\begin{array}{l}\text { Estimated height in } \\
\text { males }(\mathbf{n = 5 5})\end{array}$ & $\begin{array}{l}\text { Estimated height in } \\
\text { females }(\mathbf{n}=\mathbf{4 5})\end{array}$ \\
\hline $\begin{array}{l}\text { Right Digit } \\
\text { (Total Length) }\end{array}$ & $\begin{array}{l}0.991 \\
(\mathrm{p}=0.000)\end{array}$ & $\begin{array}{l}0.990 \\
(\mathrm{p}=0.000)\end{array}$ & $\begin{array}{l}0.980 \\
(\mathrm{p}=0.000)\end{array}$ \\
\hline $\begin{array}{l}\text { Left Digit } \\
\text { (Total Length) }\end{array}$ & $\begin{array}{l}0.993 \\
(\mathrm{p}=0.000)\end{array}$ & $\begin{array}{l}0.991 \\
(\mathrm{p}=0.000)\end{array}$ & $\begin{array}{l}0.982 \\
(\mathrm{p}=0.000)\end{array}$ \\
\hline
\end{tabular}

[Correlation is significant at the 0.01 level (2-tailed test)]

The estimated height by multiplying the total digital length with five (05) in both right and left hands were found to be similar with the measured height. Pearson correlation analysis had suggested highly positive statistical significant correlation between estimated height and measured height in all participants, males and females.

\section{Discussion}

Stature is one of the most important elements in the identification as all human physical description about an individual in order to be identified is based on stature. ${ }^{1,5}$ Though estimation of stature from long bones were preferable with higher correlation coefficient, practical difficulty arose with dismembered body parts. The height of a person in an erect position (stature) had a direct proportional relationship with the body parameters of that individual. ${ }^{4,5,6,7}$ Various studies had indicated that anthropometric parameters of the upper extremity were reliable variables that could be used to estimate individual height. ${ }^{5}$ The similar was observed in the present study where estimated height from five digits correlated with measured height.

The Forensic investigators were exploring different body parts to estimate stature from new parameters such as head, face, hand, foot, phalanges, finger length etc. ${ }^{4}$ In the present study, digits of both right and left hands were taken as parameter to measure the stature of the individual and a statistical significant correlation $(\mathrm{p}$ $=0.000)$ was found in between estimated stature and the digital length by direct multiplying factor. The multiplication factor might be used as a handy tool and proved vital in situation with complex mathematical 
equations or was dealing with number of cases in mass disaster. ${ }^{6}$ In the present study, the direct relation of height was established to fingers of the upper limb (hand) with a with multiplication factor five.

Mean stature, higher in males as compared to females ${ }^{3}$ was found similar with the present study. Females had higher correlation than males. ${ }^{6}$ In the present study, both males and females had similar correlation and it was observed with both right and left hands $(p=0.000)$. Different parts of the body had different ratios to the height of individual that differs from one population to another depending upon ethnical differences and environmental factors. ${ }^{5}$ Calculated stature was found close to the actual height with $\pm 5 \mathrm{~cm}$ difference in most of the cases ${ }^{6}$ which was not similar in the present study, where calculated stature was similar to the measured height in both males and females.

Estimation of stature from bones especially longer bones were preferable because of higher correlation coefficient and small error of estimate. All the fingers ring finger was the best to calculate height of the individual. ${ }^{7}$ All the three phalanges of each finger, studied for stature estimation in both the sex had the evident that as the range of error of stature estimation remains almost same from all the phalanges therefore any phalangeal may be used for this purpose. ${ }^{3}$ In the present study, all the phalanges of all five fingers were used to estimate the stature.

\section{Conclusion}

Correlating the anthropometric parameters might serve as a feet step in identifying the individual. Identification by estimating stature in mutilated especially by long bones is a tedious and time consuming process which involves cleaning and preparing of bones. Stature can be estimated from actual as well as by measuring the length of five digits of hand by the formula, Estimated Stature $=$ Total length of digits (Right/Left hand) $\mathrm{x} 5$. Calculated statures from the equations are close to the actual height and direct positive statistical significant correlation was found between the stature and total length of five digits of hands. So, this can be concluded that the equation may be helpful to obtain approximate stature when there is difficulty in obtaining a direct measurement or an amputed hand with intact all digits is available. This can be immensely useful in forensic anthropology and any anthropological research.

\section{Limitations}

The study was conducted in a particular age (18 to 23 years) group. It is needed to be conducted among all the age groups with extremes of age to observe any presence of variations.

\section{Acknowledgement}

First year medical students of 2013-2014 batch in Regional Institute of Medical Sciences (RIMS), Imphal, were acknowledged for their participation and support to successful completion of this study.

\section{References}

[1]. Chikhalkar BG. Estimation of stature from measurements of long bones, hand and foot dimensions. J Indian Acad Forensic Med. 2010;32(4):329-31.

[2]. Athwale MC. Estimation of height from length of forearm bones. A study on 100 Maharashtrian male adults of age 25-30. American Journal of Physical Anthropology 1963;21:105-12.

[3]. Jasuja OP, Singh G. Estimation of stature from hand and phalangeal length. JIAFM 2004;26(3):100-06.

[4]. Tyagi AK, Kohli A, Verma SK, Aggarwal BB. Correlation between stature and finger Length, International journal of medical toxicology and legal medicine 1999;1:20-2.

[5]. Ugbem LP, Godfrey EU, Ojim EE, Ejuiwa MC. Correlation between height and selected anthropometric parameters of the upper limbs of the Efiks people in Cross River State, Nigeria. J Pharm Biomed Sci 2016;6(1): 47-50.

[6]. Bardale RV, Dahodwala TM, Sonar VD. Estimation of stature from index and ring finger length. J Indian Acad Forensic Med 2013;35(4):353-7.

[7]. Susellama D, Gayathri P, Deepti S, Chandra Mohan M, Uday Kumar M, Amarnath. Study of correlation between stature and length of fingers. Sch. J. App. Med. Sci. 2014;2(2D): 773-84. 